\title{
SELF-ESTEEM IN PEOPLE WITH PHYSICAL DISABILITIES: DIFFERENCES BETWEEN ACTIVE AND INACTIVE INDIVIDUALS
}

\author{
Dagmar Nemček \\ Department of Sport Educology and Sport Humanities, Faculty of Physical Education and Sport, \\ Comenius University in Bratislava
}

\begin{abstract}
Summary: The aim of the study was to determine the status of SE in people with physical disabilities (PwPD) and compare SE scores between active and inactive individuals. The sample of PwPD $(n=186)$ was divided into two groups of those who are regularly participating in sport (active; $n=88$ ) and those who are not participating in any sport in their leisure (inactive; $\mathrm{n}=98$ ). The Rosenberg Self-Esteem Scale (RSES) was used as a primary research method. 10-item scale measures global self-worth by measuring positive and negative feelings about the self. Higher scores (from 10 to 40 points) indicate higher SE. The Pearson chi-square test was used to determine the differences of 10 RSES items and total scores between active and inactive PwPD. We found that the mean score of RSES in PwPD was 28.83 points; active PwPD observed total score of RSES 30.01 points and group of inactive PwPD showed the lowest SE by achieving 27.76 points. Mean scores comparison of each RSES item between active and inactive PwPD revealed higher SE in the group of active PwPD. Significantly higher SE was presented by 4 from 10 RSES items and by total score in the group of active PwPD. The results of our study confirmed that actively living PwPD have significantly higher SE comparing those PwPD who are living sedentary life style.
\end{abstract}

Key Words: Rosenberg self-esteem scale, items, participation in sport, physical disability

DOI 10.1515/afepuc-2017-0004

(C) Acta Facultatis Educationis Physicae Universitatis Comenianae 


\section{Introduction}

Self-esteem (SE) has become a household word. Teachers, parents, therapists, and others have focused efforts on boosting self-esteem, on the assumption that high self-esteem will cause many positive outcomes and benefits (Baumeister et al. 2003). SE is considered integral to the self-concept, and can be defined in terms of positive feelings about the self (Uchida, March \& Hashimoto 2015). It is integral to an individual's sense of their own value (Fox \& Corbin 1989; Sonstroem 1997), a principal component of mental health (Jambor \& Elliott 2005), a strong indicator of a healthy lifestyle (Hintermair 2007; Bendíková 2010; Bendíková 2014), and an important indicator of well-being (Shek \& McEwen 2012; Nemček 2016a). Although minority groups, like people with disabilities, often suffer stigmatization (Jambor \& Elliott 2005; Johnson \& Yarhouse 2013) and poor SE (Salehi et al. 2014), it is widely believed that membership of such a group has a protective effect on SE because of the tendency to identify with the minority group (Crocker \& Major 1989; Jambor \& Elliott 2005).

Promotion of health and quality of life for disabled people is one of the World Health Organization's objectives. According to the WHO (2014), disability is a set of physical or mental impairments that deprive the individual of independent personal and social life. Almost everyone experiences temporary or permanent disability at some point of life (WHO, 2012). In the comprehensive guide to disability right laws, a disabled person is someone who, according to medical commission of the Welfare Organization, suffers physical, mental, psychological or combined damage with ongoing and substantial impairment in his general health and function, and reduction in his social and economic independence. Based on this guide, disabilities are categorized into 6 major and common groups including physical-motor, mental, visual, and hearing, speech and psychiatry (WHO 2014).

One way of boosting SE is participation in sport (Labudová, Nemček \& Kraček 2015; Bendíková \& Labudová 2012). There are numerous benefits of sport participation in terms of both physical and psychological well-being (e.g., self-esteem). SE is an important psychological variable (Bardel, Fontayne, Colombel \& Schiphof 2010) and facet of personality (Adie, Duda, \& Ntoumanis 2008) in competitive sport. Adie, Duda, \& Ntoumanis (2008) demonstrated that individuals with higher SE tend to perceive competitive sport as challenging, whereas individuals with lower SE regard it as threatening. Although it is well known that participation in sport (at the recreational and elite level) can promote well-being not only among healthy athletes but also those with non-communicable diseases (Onagbiye, Moss \& Cameron 2016; Moss et al. 2016; Bendíková \& Nemček 2016) and disabilities 
(Kurková 2010; Uchida Marsh \& Hashimoto 2015; Nemček 2016b; Nemček 2016c). Highlevel competitive athletes participate in sport under conditions that present considerable physical and psychosocial stressors (Lundqvist 2011). Elite athletes (healthy as well with disabilities) must continually strive for success in a highly competitive and stressful environment; thus, high-level competitive sport can have either a detrimental or beneficial influence on the wellbeing and health of athletes (Kurková, Válková \& Scheetz 2011; Bartholomew et al. 2011).

Considering the previous research findings, the aim of our research was to determine the status of SE in people with physical disabilities (PwPD); analyze SE total scores as well as Rosenberg Self-Esteem Scale items scores in the groups of active and inactive PwPD and compare SE between actively living PwPD and those who living sedentary life style (inactive). We hypothesized that SE scores represented by all ten items of as well as overall SE score will be significantly higher in PwPD who regularly participating in physical activity and sport (active) comparing inactive individuals with PD.

\section{Methods}

\section{Participants and procedure}

Group of PwPD $(\mathrm{n}=186)$ were recruited for the study. The sample was divided into active participants $(\mathrm{n}=88)$ who regularly participated in physical activity and sport at least two time per week and inactive $(\mathrm{n}=98)$ who did not participate in any sport in their leisure time. Participants were contacted through representatives of national organisations and schools all around Slovakia unifying people with special needs. Some questionnaires were sent electronically by representatives of the organisations and some were passed out at the different meetings organised by national organisations. Pupils of special schools filled out the questionnaires during their classes with school principal permission. All data were collected during two years period $(2013-2014)$. All participants with physical disabilities (PD) agreed participate in the study and gave their written informed consent.

\section{The Rosenberg Self-Esteem Scale (RSES)}

A 10-item scale that measures global self-worth by measuring both positive and negative feelings about the self: (1) On the whole, I am satisfied with myself; (2) At times I think I am no good at all; (3) I feel that I have a number of good qualities; (4) I am able to do 
things as well as most other people; (5) I feel I do not have much to be proud of; (6) I certainly feel useless at times; (7) I feel that I'm a person of worth, at least on an equal plane with others; (8) I wish I could have more respect for myself; (9) All in all, I am inclined to feel that I am a failure; (10) I take a positive attitude toward myself (Rosenberg, 1965). The RSES is believed to be uni-dimensional. All items are answered using a 4-point Likert scale format ranging from strongly agree to strongly disagree. Items 2, 5, 6, 8, 9 are reverse scored. Scale format ranging is categorised as follows: "Strongly Disagree" (SD) - 1 point, "Disagree" (D) - 2 points, "Agree" (A) - 3 points, and "Strongly Agree" (SA) - 4 points and the scores summate for all ten items (total score). Higher scores (for each item as well as for total score) indicate higher SE. In this study a Slovak version of the RSES was used (Nemček, Labudová \& Oršulová 2014).

\section{Data analyses}

Statistical analysis was performed using SPSS v. 15.0. Qualitative variables are presented as proportion and percentage. Quantitative variables are presented as mean. Pearson chi-square test was used to determine the differences between the two groups (active and inactive) of people with physical disabilities. In current study, only one measurement has been made and one main group formed the study. The level of statistical significance was set at $p$ $<.05$.

\section{Results}

\section{Participants}

In the research participated $47.3 \%$ of actively living PwPD (active) and $52.7 \%$ inactive individuals with PD. The active group of participants is presented by higher number of men $(60.2 \%)$ in range of 15-29 years of age $(62.5 \%)$. On the other hand the highest number of inactive PwPD was represented mostly by women (58.2 \%) also in range of 15 - 29 years of age $(46.9 \%)$. The highest numbers of participants of both evaluated groups had cerebral palsy and amputees of lower and upper limbs. Basic participant's characteristics are presented in Table 1. 
Table 1

Data of the 186 participants

\begin{tabular}{|l|l|c|c|}
\hline \multicolumn{2}{|l|}{ Basic characteristics of participants } & \multicolumn{2}{|c|}{$\begin{array}{c}\text { Sport participation of PwPD } \\
\text { n (\%) }\end{array}$} \\
\cline { 3 - 4 } \multicolumn{2}{|l}{} & \multicolumn{1}{|c|}{ Active } & Inactive \\
\cline { 3 - 4 } & & $88(47.3)$ & $98(52.7)$ \\
\hline \multirow{3}{*}{ Agender } & Men & $53(60.2)$ & $41(41.8)$ \\
\cline { 2 - 4 } & Women & $35(39.8)$ & $57(58.2)$ \\
\cline { 2 - 4 } & Range 15-29 yrs & $55(62.5)$ & $46(46.9)$ \\
\cline { 2 - 4 } & Range 30-44 yrs & $16(18.2)$ & $18(18.4)$ \\
\cline { 2 - 4 } & Range 45-59 yrs & $13(14.8)$ & $17(17.3)$ \\
\cline { 2 - 4 } & Range 60+ yrs & $4(4.5)$ & $17(17.3)$ \\
\hline \multirow{5}{*}{ Type of PD } & Cerebral palsy & $28(31.8)$ & $38(38.8)$ \\
\cline { 2 - 4 } & Amputees & $27(30.7)$ & $25(25.5)$ \\
\cline { 2 - 4 } & Progressive muscular dystrophy & $16(18.2)$ & $19(19.4)$ \\
\cline { 2 - 4 } & Spine cord injury & $14(15.9)$ & $12(12.1)$ \\
\cline { 2 - 4 } & Spina bifida & $2(2.3)$ & $2(2.0)$ \\
\cline { 2 - 4 } & Sclerosis multiplex & $1(1.1)$ & $2(2.0)$ \\
\hline
\end{tabular}

\section{RSES}

The highest SE in the group of PwPD is presented by item number 3, when $24.7 \%$ of respondents strongly agreed and $61.3 \%$ agreed that they have a number of good qualities (Table 2). High number of PwPD declared high SE also by items number 7 and 10, when $25.8 \%$ of them strongly agreed and $58.1 \%$ agreed, that they are persons of worth, at least on an equal plane with others and $31.2 \%$ of PwPD strongly agreed and $51.1 \%$ agreed, that they take a positive attitude toward themselves. The mean score of 10 assessed items showing the highest self-confidence of PwPD in statements number 10 (3.113 points), 3 (3.097 points) and 7 (3.081 points). It means that PwPD take very positive attitude toward them, they have a number of good qualities and they are persons of worth, at least on an equal plane with others.

On the other hand, the lowest SE of PwPD was presented by item number 8, when only $13.4 \%$ of them strongly disagreed and $25.3 \%$ disagreed and more than half of them strongly agreed and agreed (61.3\%), that they could have more respect for themselves (Table 2). Low SE was presented also by item number 6, when only $15.0 \%$ of PwPD strongly disagreed and $35.5 \%$ disagreed that they certainly feel useless at times. Results about low SE also point to item number 2, when $40.9 \%$ of PwPD strongly agree and agree with the statement, that at times, they think they are not good at all. The lowest SE presented by mean score show items number 8 (2.349 points), 6 (2.516 points) and 2 (2.720 points). It means, that PwPD wish they could have more respect for themselves, they certainly feel useless at time and at times they think they are not good at all. 
Table 2

RSES of PwPD $(n=186)$

\begin{tabular}{|l|c|c|c|c|c|}
\hline \multirow{2}{*}{ Items } & \multicolumn{3}{|c|}{ Scale format ranging (\%) } & \multirow{2}{*}{ Mean } \\
\cline { 2 - 5 } & SA & A & D & SD & \\
\hline On the whole, I am satisfied with myself. & 21.0 & 52.7 & 24.2 & 2.2 & 2.925 \\
\hline At times, I think I am no good at all. & 10.8 & 30.1 & 35.5 & 23.7 & 2.720 \\
\hline I feel that I have a number of good qualities. & 24.7 & 61.3 & 12.9 & 1.1 & 3.097 \\
\hline I am able to do things as well as most other people. & 23.7 & 50.0 & 22.0 & 4.3 & 2.930 \\
\hline I feel I do not have much to be proud of. & 6.5 & 18.3 & 36.6 & 38.7 & 3.075 \\
\hline I certainly feel useless at times. & 14.0 & 35.5 & 35.5 & 15.0 & 2.516 \\
\hline $\begin{array}{l}\text { I feel that I'm a person of worth, at least on an } \\
\text { equal plane with others. }\end{array}$ & 25.8 & 58.1 & 14.5 & 1.6 & 3.081 \\
\hline I wish I could have more respect for myself. & 17.2 & 44.1 & 25.3 & 13.4 & 2.349 \\
\hline All in all, I am inclined to feel that I am a failure. & 2.7 & 25.3 & 44.1 & 28.0 & 2.973 \\
\hline I take a positive attitude toward myself. & 31.2 & 51.1 & 15.6 & 2.2 & 3.113 \\
\hline Total score & \multicolumn{3}{|l|}{} & $\mathbf{2 8 . 8 3}$ \\
\hline
\end{tabular}

Possible item score range is 1-4 and possible total score range is 10-40; higher mean scores indicate higher SE

The highest SE in the group of active PwPD is presented by item number 10, when $33.0 \%$ of respondents strongly agreed and $55.7 \%$ agreed that they take a positive attitude toward themselves (Table 3). High number of active PwPD declared high SE also by items number 7 and 3, when $28.4 \%$ of them strongly agreed and $59.1 \%$ agreed, that they are persons of worth, at least on an equal plane with others and $28.4 \%$ of active PwPD strongly agreed and $58.0 \%$ agreed, that they have a number of good qualities. The mean score of 10 assessed items showing the highest self-worth of active PwPD in statements number 10 (3.193 points), 5 (3.148 points) and 7 (3.148 points). It means that active PwPD take very positive attitude toward them, they are very proud of themselves and they are persons of worth, at least on an equal plane with others.

On the other hand, the lowest SE of active PwPD was presented by item number 8 , when only $14.8 \%$ of them strongly disagreed and $33.0 \%$ disagreed and more than half of them strongly agreed and agreed (52.3\%), that they could have more respect for themselves (Table 3). Low SE was presented also by item number 6 , when only $20.5 \%$ of active PwPD strongly disagreed and $38.6 \%$ disagreed that they certainly feel useless at times. Concerning to the mean score, the lowest SE of active PwPD was presented by items number 8 (2.511 points), 6 (2.727 points) and 1 (2.943 points). It means they actively living PwPD wish they 
could have more respect for themselves, they certainly feel useless at time and they are not very satisfied with themselves.

Table 3

RSES of active PwPD $(n=88)$

\begin{tabular}{|c|c|c|c|c|c|}
\hline \multirow[t]{2}{*}{ Items } & \multicolumn{4}{|c|}{ Scale format ranging $(\%)$} & \multirow[t]{2}{*}{ Mean } \\
\hline & SA & A & $\mathrm{D}$ & SD & \\
\hline On the whole, I am satisfied with myself. & 23.9 & 50.0 & 22.7 & 3.4 & 2.943 \\
\hline At times, I think I am no good at all. & 3.4 & 27.3 & 36.4 & 33.0 & 2.989 \\
\hline I feel that I have a number of good qualities. & 28.4 & 58.0 & 11.4 & 2.3 & 3.125 \\
\hline I am able to do things as well as most other people. & 25.0 & 52.3 & 18.2 & 4.5 & 2.977 \\
\hline I feel I do not have much to be proud of. & 3.4 & 19.3 & 33.0 & 44.3 & 3.182 \\
\hline I certainly feel useless at times. & 6.8 & 34.1 & 38.6 & 20.5 & 2.727 \\
\hline $\begin{array}{l}\text { I feel that I'm a person of worth, at least on an } \\
\text { equal plane with others. }\end{array}$ & 28.4 & 59.1 & 11.4 & 1.1 & 3.148 \\
\hline I wish I could have more respect for myself. & 11.4 & 40.9 & 33.0 & 14.8 & 2.511 \\
\hline All in all, I am inclined to feel that I am a failure. & 0.0 & 27.3 & 34.1 & 38.6 & 3.114 \\
\hline I take a positive attitude toward myself. & 33.0 & 55.7 & 9.1 & 2.3 & 3.193 \\
\hline \multicolumn{5}{|l|}{ Total score } & 30.01 \\
\hline
\end{tabular}

Possible item score range is 1-4 and possible total score range is 10-40; higher mean scores indicate higher SE

The highest SE in the group of inactive PwPD is presented by item number 3, when $21.4 \%$ of respondents strongly agreed and $64.3 \%$ agreed that they have a number of good qualities (table 4). High number of inactive PwPD declared high SE also by items number 7 and 10 , when $23.5 \%$ of them strongly agreed and $57.1 \%$ agreed, that they are persons of worth, at least on an equal plane with others and 29.6 \% of inactive PwPD strongly agreed and $46.9 \%$ agreed, that they take a positive attitude toward themselves. The mean score of 10 assessed items showing the highest self-worth of inactive PwPD in statements number 3 (3.071 points), 10 (3.041 points) and 7 (3.020 points). It means that inactive PwPD feel that they have a number of good qualities, take a positive attitude toward them, they are persons of worth, at least on an equal plane with others.

On the other hand, the lowest SE of inactive PwPD was presented by same item as group of active PwPD and it is item number 8 , when only $12.2 \%$ of them strongly disagreed and $18.4 \%$ disagreed that they could have more respect for themselves and more than half of them strongly agreed and agreed (69.3\%) with the statement (table 4). Low SE was presented also by item number 6 (same as group of active PwPD), when only $10.2 \%$ of inactive PwPD strongly disagreed and $32.7 \%$ disagreed that they certainly feel useless at times. We can also 
pay attention to item number 2, where $50 \%$ of inactive respondents with PD strongly agree and agree with the statement, that at times, they think they are not good at all. Concerning to the mean score, the lowest SE of inactive PwPD was presented by items number 8 (2.204 points), 6 (2.327 points) and 2 (2.480 points). It means, that inactive PwPD wish they could have more respect for themselves, they certainly feel useless at time and at times, they think they are no good at all.

Table 4

RSES of inactive PwPD $(n=98)$

\begin{tabular}{|c|c|c|c|c|c|}
\hline \multirow[t]{2}{*}{ Items } & \multicolumn{4}{|c|}{ Scale format ranging $(\%)$} & \multirow[t]{2}{*}{ Mean } \\
\hline & SA & A & $\mathrm{D}$ & SD & \\
\hline On the whole, I am satisfied with myself. & 18.4 & 55.1 & 25.5 & 18.4 & 2.908 \\
\hline At times, I think I am no good at all. & 17.3 & 32.7 & 34.7 & 15.3 & 2.480 \\
\hline I feel that I have a number of good qualities. & 21.4 & 64.3 & 14.3 & 0.0 & 3.071 \\
\hline I am able to do things as well as most other people. & 22.4 & 48.0 & 25.5 & 4.1 & 2.888 \\
\hline I feel I do not have much to be proud of. & 9.2 & 17.3 & 39.8 & 33.7 & 2.980 \\
\hline I certainly feel useless at times. & 20.4 & 36.7 & 32.7 & 10.2 & 2.327 \\
\hline $\begin{array}{l}\text { I feel that I'm a person of worth, at least on an } \\
\text { equal plane with others. }\end{array}$ & 23.5 & 57.1 & 17.3 & 2.0 & 3.020 \\
\hline I wish I could have more respect for myself. & 22.4 & 46.9 & 18.4 & 12.2 & 2.204 \\
\hline All in all, I am inclined to feel that I am a failure. & 5.1 & 23.5 & 53.1 & 18.4 & 2.847 \\
\hline I take a positive attitude toward myself. & 29.6 & 46.9 & 21.4 & 2.0 & 3.041 \\
\hline \multicolumn{5}{|l|}{ Total score } & 27.76 \\
\hline
\end{tabular}

Possible item score range is 1-4 and possible total score range is 10-40; higher mean scores indicate higher SE

Mean scores comparison of each RSES item between active and inactive PwPD revealed higher SE in the group of active PwPD, even only four (items number 2, 6, 8 and 9) from 10 items showed significant differences (table 5). SE total score in active PwPD was 30.01 (Table 3) and in inactive PwPD 27.76 (Table 4). This observed data presented significantly higher SE in the group of active PwPD comparing inactive group of respondents at $\mathrm{p}<.05$ (table 5). Active PwPD declared significantly higher SE in RSES reverse scored items number 2, 6, 8 and 9 what means, that active PwPD significantly higher disagreed with mentioned RSES items comparing inactive PwPD. 
Table 5

RSES differences between active and inactive PwPD

\begin{tabular}{|l|c|c|}
\hline Items & $\boldsymbol{\chi}^{\mathbf{2}}$ & Sign. level \\
\hline On the whole, I am satisfied with myself. & 2.276 & $\mathrm{~ns}$ \\
\hline At times, I think I am no good at all. & $\mathbf{1 4 . 9 6 * *}$ & $\mathrm{p}<.01$ \\
\hline I feel that I have a number of good qualities. & 3.751 & $\mathrm{~ns}$ \\
\hline I am able to do things as well as most other people. & 1.453 & $\mathrm{~ns}$ \\
\hline I feel I do not have much to be proud of. & 4.446 & $\mathrm{~ns}$ \\
\hline I certainly feel useless at times. & $\mathbf{9 . 9 2 1 *}$ & $\mathrm{p}<.05$ \\
\hline $\begin{array}{l}\text { I feel that I'm a person of worth, at least on an equal } \\
\text { plane with others. }\end{array}$ & 1.849 & $\mathrm{~ns}$ \\
\hline I wish I could have more respect for myself. & $\mathbf{7 . 8 1 9 *}$ & $\mathrm{p}<.05$ \\
\hline All in all, I am inclined to feel that I am a failure. & $\mathbf{1 5 . 3 5 * *}$ & $\mathrm{p}<.01$ \\
\hline I take a positive attitude toward myself. & 5.400 & $\mathrm{~ns}$ \\
\hline Total score & $\mathbf{1 0 . 7 2 *}$ & $\mathrm{p}<.05$ \\
\hline
\end{tabular}

\section{Discussion}

Although individuals with disabilities often report an absence of positive life experiences because of their disadvantaged social position (Tam 1998), our results, among the others, also confirmed that regular participation in physical activity and sport is the ideal tool to increase SE not only in healthy population but also in PwPD. The results of our study presented: (a) the status of RSES in PwPD; (b) the SE status of those who regularly participating in physical activity and sport; (c) the SE of PwPD who not participating in any sport in their leisure time and (d) the RSES comparison between active and inactive individuals with PD.

The mean score of RSES in PwPD was 28.83 points, active PwPD reached RSES total score of 30.01 points and group of inactive PwPD achieved the lowest SE total score with 27.76 points. King et al.'s (1993) study showed the lack of difference between SE scores in disabled and healthy individuals and based on their results suggested that clinical care approach not to be determined assuming that disabled people have lower SE.

Data analyses of the current study have showed, that PwPD in general, and actively living PwPD present their higher SE by taking very positive attitude toward them. Inactive PwPD declare the highest SE by feeling that they have a number of good qualities. Findings further presents that the lowest SE in all evaluated groups of PwPD, no matter if they 
participating in sport or not, was declared by wishing they could have more respect for themselves.

Heydari et al. (2009) showed the difference of SE between disabled and normal students. They found that SE and life satisfaction (LS) is lower in physically disabled people than in normal people. Similar study of Bendíková \& Nemček (2016) presented the comparison of LS scores between active and inactive healthy participants (HP; $n=313$ ) and active and inactive people with noncommunicable diseases (NCDs; $n=351$ ). The results of the study demonstrate no significant differences in LS score between active and inactive HP none in one evaluated LS statement neither in overall LS score but the mean scores of all assessed LS statements as well as total mean score pointed to higher LS in group of active HP comparing inactive HP. On the other hand, the LS of active people with NCDs was significantly higher presented by all five statements scores and the overall LS score too.

Another investigation confirmed the lowest SE in the group of sedentary people with disabilities (Nemček 2016d) and the highest SE in the group of active HP (Bendíková \& Nemček 2016). Nemček (2013) surveyed people with different kinds of disabilities and found no significant differences between genders in SE score, but mean scores declared higher SE in women than men. Differences between active and sedentary people with disabilities show that those, who prefer active life style and participating in sport (elite and sport for all levels) are more satisfied with their life than those who are not participating in sport at all (Nemček et al., 2014). Based on current scientific evidence we couldn't confirm the hypothesis, where we assumed, that SE scores represented by all ten items of RSES as well as overall SE score will be significantly higher in PwPD who regularly participating in physical activity and sport compare inactive PwPD. Although total score shows significantly higher SE in active PwPD, but only 4 from 10 RSES items reveal significantly higher SE in active PwPD compare inactive.

\section{Conclusion}

Based on the aim of the current study, we found that:

- PwPD and actively living PwPD present higher SE by taking very positive attitude toward them. Inactive PwPD declare the highest SE by feeling that they have a number of good qualities.

- The lowest SE in all evaluated groups of PwPD, no matter if they participating in sport or not, was declared by wishing they could have more respect for themselves. 
- Mean scores of each RSES item as well as of RSES total score point to higher SE in actively living PwPD. Significantly higher SE showed active PwPD in four RSES items and in reached SE total score.

Generally we can say that the evaluation of SE by the RSES items shows that it is a suitable tool to asses SE in the population with disabilities. The results of our study, mean scores as well as level of significance confirmed, that active PwPD achieving higher SE assessed by RSES items. We recommend, that it is essential to increase participation in sports, because such participation can empower people with disabilities to set and attain goals and reach a higher SE and quality of life on their own terms.

\section{References}

1. ADIE, J. W., J. L. DUDA \& N. NTOUMANIS, 2008. Achievement goals, competition appraisals, and the psychological and emotional welfare of sport participants. In: Journal of Sport and Exercise Psychology. 30(3): 302-322.

2. BARDEL, M., P. FONTAYNE, F. COLOMBEL \& L. SCHIPHOF, 2010. Effects of match result and social comparison on sport state self-esteem fluctuations. In: Psychology of Sport and Exercise. 11(3): 171-176.

3. BARTHOLOMEW, K. J., N. NTOUMANIS, R. M. RYAN \& C. THOGERSENNTOUMANI, 2011. Psychological need thwarting in the sport context: Assessing the darker side of athletic experience. In: Journal of Sport and Exercise Psychology. 33(1): 75-02.

4. BAUMEISTER, R. F., J. D. CAMPBELL, J. I. KRUEGER \& K. D. VOHS, 2003. Does high selfesteem cause better performance, interpersonal success, happiness, or healthier lifestyles? In: Psychological Science in the Public Interest, 4(1): 1-44.

5. BENDÍKOVÁ, E., 2010. Význam pohybovej aktivity $\mathrm{v}$ spôsobe života senioriek. [Meaning of physical activity in senior's life style]. In. Telesná výchova a šport [Physical Education and Sport]. 20(4): 10-15.

6. BENDÍKOVÁ, E., 2014. Lifestyle, physical and sports education and health benefits of physical activity. In: European researcher : international multidisciplinary journal. 69(22): $343-348$.

7. BENDÍKOVÁ, E. \& J. LABUDOVÁ, 2012. Športové aktivity žien z hl'adiska zdravia a sociálnej inklúzie [Sport activities in women from health and social inclusion point of 
view]. In: Šport a rekreácia 2012 : zbornik vedeckých prác. [Sport and Recreation 2012 proceedings]. Nitra: UKF, PF, pp. 3-11.

8. BENDÍKOVÁ, E. \& D. NEMČEK, 2016. Life satisfaction in healthy people and people with noncommunicable diseases: Differences between active and inactive individuals. In: Sport Science. 9(2): 19-23.

9. CROCKER, J. \& B. MAJOR, 1989. Social stigma and self-esteem: The self-protective properties of stigma. In: Psychological Review. 96(4): 608-630.

10. FOX, K. R. \& C. B. CORBIN, 1989. The physical self-perception profile: Development and preliminary validation. In: Journal of Sport and Exercise Psychology. 11(4): 408-430.

11. HEYDARI, A., R. MASHAK \& H. DARVISHI, 2009. Compare of the Self-Efficacy, Loneliness, Fear of success and Satisfaction in Physically Disabled Students with Normal Students in Ahvaz Islamic Azad University. In: New Find Psychology. 10(4): 7-26.

12. HINTERMAIR, M. 2007. Self-esteem and satisfaction with life of deaf and hardofhearing people: A resource-oriented approach to identity work. In: Journal of Deaf Studies and Deaf Education. 13(2): 278-300.

13. JAMBOR, E. \& M. ELLIOTT, 2005. Self-esteem and coping strategies among deaf students. In: Journal of Deaf Studies and Deaf Education. 10(1): 63-81.

14. JOHNSON, V. R. F. \& M. A. YARHOUSE, 2013. Shame in sexual minorities: Stigma, internal cognitions, and counseling considerations. In: Counseling and Values. 58(1): 85103.

15. KING, G. A., I. Z. SHULTZ, K. STEEL, M. GILPIN \& T. CATHERS, 1993. Selfevaluation and self-concept of adolescents with physical disabilities. In: Am J Occup Ther. 47(2): 132-140.

16. KURKOVÁ, P. 2010. Vzdělávání žáků se sluchovým postižením z hlediska vedení ke zdravému životnímu stylu. [The education of pupils who are deaf or hard of hearing from guiding to healthy life style point of view]. Olomouc: Palacky University in Olomouc. ISBN 978-80-244-2582-5.

17. KURKOVÁ, P., H. VÁLKOVÁ \& N. SCHEETZ, 2011. Factors impacting participation of European elite deaf athletes in sport. In: Journal of Sports Sciences. 29(6): 607-618.

18. LABUDOVÁ, J., J. NEMČEK \& S. KRAČEK, 2015. Šport na každý deň. [Sport for everyday]. Bratislava : END spol.s.r.o. ISBN 978-80-89324-16-3.

19. LUNDQVIST, C., 2011. Well-being in competitive sport-The feel-good factor? A review of conceptual considerations of well-being. In: International Review of Sport and Exercise Psychology. 4(2): 109-127. 
20. MOSS, OVIEDO, TAMULEVICIUS \& CAMERON, 2016. The effect of a 12-week exercise intervention on risk factors of non-communicable diseases in black African population: the B-Healthy study - a controlled trial. Avaliable from: http://www.ltmic.co.za/sessions/the-effect-of-a-12-week-exercise-intervention-on-riskfactors-of-non-communicable-diseases-in-black-african-population-the-b-healthy-study-acontrolled-trial/

21. NEMČEK, D., 2013. Life satisfaction of people with disabilities. In Theory and practice in adapted physical activity (pp. 46). Olsztyń, Poland: Olsztyńska szkola wyźsza Im. Józefa Rusieckiego.

22. NEMČEK, D., 2016(a). Cognitive element of subjective well-being of the Slovak population. In: Physical Activity, Health and Prevention: International Scientific Conference. Žilina : IPV Institute of Education, pp. 62-67.

23. NEMČEK, D., 2016(b). Quality of life of people with disabilities: differences in satisfaction with indicators and domains between active and inactive individuals. In: Physical Activity Review. 4(4): 62-71.

24. NEMČEK, D., 2016(c). Quality of life of people with disabilities from sport participation point of view. In: Acta Facultatis Educationis Physicae Universitatis Comenianae. 56(2): 77-92.

25. NEMČEK, D., 2016(d). Life satisfaction of people with disabilities: a comparison between active and sedentary individuals. In: Journal of Physical Education and Sport. 16(2): 1084-1088.

26. NEMČEK, D., J. LABUDOVÁ, T. JAVANAINEN-LEVONEN, \& J. WITTMANNOVÁ, 2014. Quality of life between active population and population with sedentary behavior. In: EUCAPA-European Congress of Adapted Physical Activity (pp. 1). Madrid, Spain: Universidad politécnica de Madrid.

27. NEMČEK, D., J. LABUDOVÁ \& N. ORŠULOVÁ, 2014. Self-esteem in people with disabilities. In: Acta Facultatis Educationis physicae Universitatis Comenianae. 54(2): $33-42$.

28. ONAGBIYE, S. O., S. J. MOSS, \& M. CAMERON, 2016. Managing Noncommunicable Diseases in an African Community: Effects, Compliance, and Barriers to Participation in a 4-Week Exercise Intervention. In: International Quarterly of Community Health Education. 36(3): 165-76.

29. ROSENBERG, M., 1965. Society and the adolescent self-image. Princeton, NJ: Princeton University Press. 
30. SALEHI, M., K. H. TAVAKOL, M. SHABANI, \& T. ZIAEI, 2014. The Relationship Between Self-Esteem and Sexual Self-Concept in People With Physical-Motor Disabilities. In: Iranian Red Crescent Medical Journal. 17(1): 1-7.

31. SHEK, Y. L. \& M. K. McEWEN, 2012. The relationships of racial identity and gender role conflict to self-esteem of Asian American undergraduate men. In: Journal of College Student Development, 53(5): 703-718.

32. SONSTROEM, R. J. 1997. Exercise and selfesteem. In W. P. Morgan (Ed.), Exercise and mental health (pp. 128-143). Washington, DC: Taylor \& Francis.

33. TAM, S. 1998. Comparing the self-concepts of persons with and without physical disabilities. In: Journal of Psychology. 132: 78-86.

34. UCHIDA, W., H. MARSH \& K. HASHIMOTO, 2015. Predisctors and correlates of selfesteem in deaf athletes. In: European Journal of Adapted Physical Activity. 8(1): 21-30.

35. WHO, 2014. Disabilities and rehabilitation. WHO. Available from: http://www.who.int/disabilities/world_report/2011/en/.

36. WHO, 2012. World Bank (2011): World report on disability. Malta: WHO. 